\title{
Terapia complementar em área endêmica de filariose bancroftiana, pelos Clubes da Esperança
}

\author{
Hope Clubs as adjunct therapeutic measure \\ in bancroftian filariasis endemic areas
}

\author{
Gerusa Dreyer $^{1,2}$, Joaquim Norões ${ }^{1,3}$ e Denise Mattos $^{1}$
}

\begin{abstract}
RESUMO
Em 1997, a Organização Mundial de Saúde anunciou um ambicioso projeto de eliminação global da filariose linfática como problema de saúde pública. Esse projeto baseia-se em dois pilares: interrupção da transmissão e controle da morbidade. Experiência em Recife-Brasil, área endêmica de filariose bancroftiana, mostrou que a criação pioneira de Clubes da Esperança pode contribuir, a baixo custo, como terapia coadjuvante importante na melhoria da qualidade de vida dos portadores de linfedema e de quilúria. Os pacientes compreendem os fundamentos básicos e os utilizam na prevenção dos episódios agudos bacterianos de pele (erisipelas) e na manutenção da urina sem o componente quiloso. Eles sentem que não estão sós e, através de ações especializadas e do trabalho em grupo, readquirem o potencial para o trabalho produtivo, realizando também mudanças substancialmente positivas dentro de suas comunidades, agindo, assim, como amplificadores do processo.
\end{abstract}

Palavras-chaves: Clube da Esperança. Filariose bancroftiana. Elefantíase. Quilúria. Qualidade de vida. Social.

\begin{abstract}
In 1997 the World Health Organization announced an ambitious project called the Global Program to Eliminate Lymphatic Filariasis, as a Public Health Problem. The program is based on two pillars: interruption of transmission and morbidity control. Experience in Recife, Brazil, an endemic area for bancroftian filariasis, showed that an innovative approach called Hope Clubs, can equip lymphedema patients with the skills, motivation, and enthusiasm to sustain effective, low-cost and convenient self-care to prevent acute skin bacterial episodes and milky urine in the case of chyluria carriers. They feel they are not alone, they regain their potential for productive work and are able to amplify these activities throughout filariasisendemic communities.
\end{abstract}

Key-words: Hope Club. Bancroftian filariasis. Elephantiasis. Chyluria. Quality of life. Social.

Nos últimos anos, a filariose linfática, surgiu como um problema crescente de saúde pública em várias partes do mundo ${ }^{119}$. A debilitação física e o estigma social da doença, também responsáveis por perdas econômicas, colocam a filariose linfática como a segunda causa mundial de incapacidade para 0 trabalho ${ }^{28}$. 0 desenvolvimento de metodologias de diagnóstico individual ${ }^{27}$ e de tratamento ${ }^{23}$ proporcionou novos horizontes para que, no cenário global, a infecção/doença pudesse não mais existir como um problema de saúde pública. Em 1993, a Força Tarefa para Erradicação de Doenças colocou a filariose linfática entre as seis doenças potencialmente elimináveis ${ }^{4}$ e, em 1997, a Assembléia Mundial da Saúde consolidou essa resolução ${ }^{29}$. Em julho, desse mesmo ano, em Townsville, Queensland, Austrália, representantes da OMS, de seus centros colaboradores, de ministérios de saúde, de organizações não-governamentais, de academias científicas e de indústrias farmacêuticas estabeleceram que o controle da filariose seria feito baseado em dois grandes pilares: a interrupção da transmissão (através do tratamento em massa das populações endêmicas) e do controle da sua morbidade ${ }^{25}$.

\footnotetext{
1. Núcleo de Ensino, Pesquisa e Assistência em Filariose do Hospital das Clínicas da Universidade Federal de Pernambuco, Recife, PE. 2. Centro de Pesquisas Aggeu Magalhaes da Fundação Oswaldo Cruz, Recife, PE. 3. Departamento de Cirurgia do Centro de Ciências da Saúde da Universidade Federal de Pernambuco, Recife, PE. Endereço para correspondência: Dr ${ }^{\mathrm{a}}$ Gerusa Dreyer. NEPAF/Hospital das Clínicas/UFPE. Av. Prof. Moraes Rego s/n, Cidade Universitária, 50740-900 Recife, PE, Brasil. Telefax: 5581 3426-4348

e-mail: dreyer-g@uol.com.br

Recebido para publicação em 11/5/2006

Aceito em 12/6/2006
} 
Estima-se que a filariose linfática (produzida pela Wuchereria bancrofti e pelas Brugias) afeta 120 milhões de pessoas e que a bancroftose, per se, aflige cerca de 100 milhões de pessoas, distribuídas em 80 países dos diferentes continentes ${ }^{30}$. A Índia detém cerca de um terço dos casos registrados no mundo, enquanto a América Latina representa $0,3 \%$ da prevalência mundial. No Brasil, as áreas reconhecidamente endêmicas são: 0 Grande Recife, em Pernambuco, de maior prevalência, e Maceió, em Alagoas. Em Belém (PA) que, no início da década de cinqüenta, existia como área de maior prevalência do país, a transmissão parece estar hoje controlada e em vias de eliminaçã $0^{18}$. Um outro traço sombrio dessa infecção é o fato de que mais de 1.1 bilhão de pessoas ou cerca de $20 \%$ da população mundial habitam as áreas endêmicas e estão sob o risco de adquirirem a infecção filarial linfática ${ }^{20}$. Nas regiões em que a doença é endêmica, a prevalência de infecção vem aumentando de forma continuada devido, principalmente, ao crescimento rápido e desordenado dos centros urbanos, o que contribui para que se amplifiquem as condições ideais para a multiplicação dos focos de mosquitos transmissores da infecção ${ }^{1}$. Estes, na sua maioria, são representados pelo Culex quinquefasciatus, conhecido no Brasil como pernilongo, mosquito, muriçoca ou carapanã.

A apresentação clínica da filariose bancroftiana é diversificada. Essa diversidade está na dependência da idade e do sexo dos pacientes infectados ${ }^{16}$. Estima-se que existam cerca de 40 milhões de portadores de manifestações crônicas da infecção ${ }^{20}$. Nas mulheres, a complicação da doença filarial predomina nos membros inferiores, através de uma forma clínica que deixa a área afetada com um aspecto que lembra a pata de um elefante - daí o nome elefantíase, utilizado universalmente para essa apresentação. Nos homens, a hidrocele, definida como o aumento do volume do escroto por acúmulo de líquido na cavidade vaginal do testículo, é a apresentação clínica mais prevalente da doença. Tanto a hidrocele quanto o edema e a elefantíase da genitália externa masculina constituem formas clínicas desfigurantes e incapacitantes da infecção filarial. Dessa forma, em ambos os sexos, a doença, por desfigurar e incapacitar, pode repercutir devastadoramente na vida afetiva e nas atividades laborais de seus portadores ${ }^{1415}$

Em 1986, no Centro de Pesquisas Aggeu Magalhães (CPqAM)/FIOCRUZ, em Recife/PE, iniciou-se um programa em filariose bancroftiana ${ }^{6}$. A partir de então, numa articulação com vários profissionais do Hospital das Clínicas da Universidade Federal de Pernambuco (HC/UFPE), foram desenvolvidos trabalhos básicos nas diversas áreas do conhecimento dessa doença, que é exclusiva do ser humano. A partir dessa parceria informal, protocolos de pesquisa clínico-cirúrgicos foram desenvolvidos e que resultou no esclarecimento de vários aspectos da doença. Entre esses esclarecimentos encontram-se o desenvolvimento de um método pioneiro para o diagnóstico/identificação do parasito adulto vivo em seu habitat natural e a descrição da forma subclínica da doença, representada pela linfangiectasia, usando-se a ultra-sonografia ${ }^{21}$. A visualização dos parasitas adultos de $W$. bancrofti por metodologia não invasiva em vasos linfáticos e linfonodos ${ }^{11} 21$ abriu uma larga avenida para um melhor entendimento de inúmeros outros aspectos da relação parasita-hospedeiro, até então desconhecidos ${ }^{17}$. Como uma outra conquista da referida parceria, pode-se ressaltar 0 desenho de um novo mecanismo para a progressão do linfedema, que foi proposto após melhor se compreender a etiologia dos episódios agudos dos indivíduos que vivem em área endêmica ${ }^{13}$. Ficou evidenciado que o desenvolvimento e a progressão do linfedema até a elefantíase se devem às infecções bacterianas sucessivas ${ }^{17}$ e que, uma vez adotadas medidas preventivas, poder-se-á interromper a evolução e reverter, até certo grau, o edema já instalado. Essa prevenção tem como base principal a higiene diária do membro afetado com água e sabã ${ }^{10}$. Conclusões semelhantes foram encontradas por pesquisadores em outros países, em áreas endêmicas de bancroftose ${ }^{22}$ e de Brugia ${ }^{3}$.

A educação do paciente portador de linfedema é um passo fundamental no seu tratamento. Deve ser usada tanto para mudar os conceitos errôneos e fatalistas pré-existentes de que a progressão da doença é inevitável, quanto para ensinar os procedimentos corretos para os cuidados diários, encorajando e motivando o paciente a participar do programa de tratamento. Impulsionado pelo novo conhecimento do importante papel da higiene pessoal e do membro afetado pelo linfedema em particular, em 1993, foi criado o Clube da Esperança $a^{8}$, nome escolhido por sugestão e votação de 72 pacientes que, na época, assiduamente, freqüentavam o ambulatório de filariose do CPqAM.

o Clube da Esperança é um programa que se alicerça nos seguintes pilares: 1) o estímulo e o treinamento dos portadores da doença e de seus familiares quanto aos cuidados de higiene. A ajuda na higiene é muito importante nos casos mais avançados; o baixo custo e a simplificação que isso acarreta criam as condições para a auto-sustentação do processo; 2) o reforço da solidariedade e da reintegração social, através de uma abordagem transdisciplinar; 3) o ensino continuado de pessoas da comunidade (sempre que possível, entre aqueles portadores de linfedema) que servem como amplificadores do processo; dessa forma, pode-se garantir o acesso aos novos conhecimentos, minimizando as distorções, principalmente aquelas introduzidas por determinadas crenças populares que podem causar dano ao paciente; por exemplo, o uso, no membro afetado, de chás quentes das mais diferentes ervas durante os episódios agudos bacterianos; 4) a cooperação com profissionais e estudantes das áreas afins, com outras associações e com autoridades locais, para facilitar a (re)inserção dos pacientes na sociedade civil organizada, com o desenvolvimento de programas educacionais e de geração de renda com auto-sustentabilidade; 5) a geração de mecanismos de amplificação desse conhecimento nas comunidades endêmicas ainda não familiarizadas com os mesmos.

Um ano após a criação do Clube da Esperança, e em decorrência dos resultados da parceria entre o CPqAM e o HC-UFPE, foi criado o Núcleo de Ensino, Pesquisa e Assistência em Filariose (NEPAF) que, em 1999, foi integrado oficialmente ao Centro de Ciências da Saúde/UFPE ${ }^{26}$. A partir de então, as reuniões dos pacientes passaram a ser coordenadas e realizadas 
pelo NEPAF. Em função da escassez cada vez maior dos recursos financeiros, principalmente pelos órgãos de fomento à pesquisa, houve a necessidade do levantamento de fundos para garantir a continuidade do trabalho iniciado. Isso levou à criação da Organização Não-governamental Amaury Coutinho ${ }^{7}$ com a finalidade de identificar e trazer doadores para garantir a continuidade tanto da pesquisa quanto da assistência especializada em filariose bancroftiana no Hospital das Clínicas da UFPE, um hospital terciário universitário. Um dos frutos desse suporte foi a implantação de um amplo projeto de caráter socioeconômicoeducacional que incluía, além do Clube da Esperança, o programa Resgate da Cidadania, amplo projeto de geração de renda autosustentável (D Mattos: comunicação pessoal). O Clube da Esperança foi estruturado em encontros sistematizados (um mínimo de seis e no máximo nove por ano) entre pacientes, familiares, estudantes universitários, profissionais e outros convidados pertencentes ou não à sociedade civil organizada. 0 resultado maior dos encontros foi a criação de oportunidades, sem precedentes, de se discutir coletivamente o que está subjacente à filariose. Sempre esteve presente a preocupação com relação à horizontalidade e à solidariedade. A busca de depoimentos dos pacientes sobre a doença, durante as reuniões, constituía a tônica maior e complementava as informações teóricas. A sensação de acolhimento se tornou o grande eixo aglutinador. A parceria entre os membros pôde ser feita porque os problemas foram divididos gerando soluções que partiram dos próprios participantes que, ao se identificarem com as semelhanças, compactuavam responsabilidades. 0 grupo fortaleceu as discussões num palco onde todo o cenário da filariose bancroftiana pôde ser apresentado porque estavam ali os seus atores vivos. A experiência com os pacientes portadores de edemas e elefantíase de membros inferiores e superiores fez abrir espaço para um subgrupo masculino de deformidades da genitália externa relacionadas à filariose. A urofilariose, em sua apresentação deformante, é capaz de provocar conflitos dos mais devastadores na vida social e afetiva de seus portadores. Dar a oportunidade a esses homens de verbalizarem, em um ambiente propício, as suas dificuldades diárias nas mais diversas áreas criou um grande vínculo de amizade entre os mesmos, que ultrapassaram os limites do clube, amplificando sua vida social.

o nascimento de um outro subclube aconteceu, contemplando, dessa vez, os pacientes de quilúria. Foi criada a sistematização da troca de informações acerca dos elementos que constituem os alimentos de uma dieta hipolipídica/ hiperprotéica - aspecto este imprescindível na condução clínica do paciente que perde na urina linfa rica em quilomícrons ${ }^{12}$. Criou-se um cenário adequado para a discussão e para a prática da culinária, aumentando a troca de experiências. 0 mito de que o sabor do alimento é dado somente pela gordura foi derrubado. Aprendeu-se que o sabor pode ser introduzido na alimentação pobre em gordura e, sobretudo, adequando-se a dieta à condição socioeconômica do paciente.

0 maior desafio, entretanto, foi a criação de um Clube da Esperança Infantil para os filhos, os netos, os vizinhos e os amigos pequeninos dos pacientes sócios do clube: ensinar a prevenção das lesões interdigitais (as famosas frieirinhas, no vocabulário infantil), induzidas pela disfunção linfática, causadas potencialmente por uma complicação da infecção bancroftiana. São essas lesões interdigitais a causa mais freqüente dos episódios agudos bacterianos de pele que ocorrem nas pessoas que vivem nas áreas endêmicas ${ }^{24}$. São os episódios bacterianos agudos de repetição que estabelecem o edema crônico e a sua progressão para a elefantíase. A higiene corporal diária, visando, de forma especial os espaços interdigitais, passou a fazer parte de uma rotina informada e consciente dessa faixa etária.

Em 1999, foi introduzida, em reuniões extraordinárias, a informação sobre a filariose em outros países, como viviam os pacientes de acordo com a economia e a cultura local, enfatizando as limitações do atendimento médico em clínicas durante os episódios agudos. Os sócios do Clube da Esperança perceberam o contraste que existia entre viver com os avanços gerados pelo clube, como a auto-ajuda, por exemplo, e o de viver sem as condições de esperança, como ocorria com os pacientes dos outros países. Quando foi concluído o programa de informação da filariose mundial, lançou-se ao grupo um desafio quanto à sua disponibilidade de repassar a filosofia do Clube da Esperança para os pacientes de outros países. A adesão foi unânime e dessa decisão - em parceria com o Centers for Diseases Control and Prevention - CDC Atlanta - EUA - foram produzidos dois vídeos educativos ${ }^{5}$ - de 21 minutos para pacientes e de 48 minutos para agentes de saúde - tendo como atores principais os próprios sócios do clube. Hoje os vídeos existem (em VHS e CD) nas versões em inglês, português, francês, espanhol e chinês e estão amplamente distribuídos nas diversas áreas endêmicas do mundo.

Ficou claro que, quando existe parceria na coresponsabilidade, as pessoas acabam-se fortalecendo num processo dialogal com a construção de seu novo conhecimento, dando condições para a quebra do círculo de isolamento social que alimenta a idéia de incapacidade tão presente nos pacientes portadores das complicações da filariose linfática, principalmente na sua deformidade maior - a elefantíase. Não só os pacientes se beneficiaram com esse projeto. Uma maior conscientização da opinião pública sobre os pacientes portadores das formas desfigurantes, nos diversos segmentos da sociedade, ajudou a própria sociedade a buscar ultrapassar as fronteiras do preconceito para diminuir a marginalização desses indivíduos.

Um fato surpreendente foi o número de pacientes portadores de edema de membro superior conseqüente à mastectomia, com esvaziamento axilar ipsi-lateral, assim como os portadores de malformação linfática, que passaram a fazer parte do clube. Como os cuidados gerais são os mesmos para os portadores de disfunção linfática, independentemente da etiologia, isso alarga os horizontes para que esse mesmo programa possa ser aventado em áreas não endêmicas, para pacientes de baixa renda e portadores de disfunção linfática das mais diversas etiologias. 


\section{CLUBES DA ESPERANÇA: UMA ESTRATÉGIA FACTÍVEL?}

A estratégia do Clube de Esperança, criado em Recife, foi realidade por mais de uma década (de 1993 a 2004), congregando mais de 1000 sócios, entre pacientes e familiares. Além dos vídeos e CDs educativos já referidos, os bons resultados foram reproduzidos em vários países endêmicos e as bases do programa de tratamento estão resumidas em um manual de 16 páginas ${ }^{9}$, nos idiomas português, criolo, inglês, árabe, francês e espanhol. A versão em inglês do manual é disponibilizada, gratuitamente, pelo Centers for Diseases Control and Prevention (CDC), Mailstop F-22, Atlanta-GA, 30341-3724, USA e através do site da OMS: www.filariasis.org/docs. As versões em português e em espanhol podem ser acessadas no site da ONG Amaury Coutinho (www.amaurycoutinho.org.br). Tanto os manuais como os vídeos/CDs educativos visam o paciente, mas também estão voltados para o treinamento dos agentes de saúde que vivem nas comunidades endêmicas5.

Os pacientes/autores dão os seus testemunhos de que essa é uma estratégia factível em área endêmica de filariose bancroftiana que ajuda a diminuir os custos médico e psicossocial da doença. Tais custos psicossociais ainda não estão e talvez nunca sejam adequadamente contabilizados ${ }^{12}{ }^{14}$. Assim, para integrar o braço de controle da morbidade ${ }^{25}$ do programa global de eliminação da filariose, a criação de Clubes da Esperança nas áreas endêmicas poderia ser pensada como uma das estratégias para garantir as ações básicas, em face da metodologia facilmente reprodutível pelos portadores, as quais lhe emprestam a maior base para a auto-sustentação. 0 Clube da Esperança mostrou que se pode mudar o olhar psicossocial sobre a filariose bancroftiana e ajudou a não perder de vista 0 objetivo da inclusão efetiva e afetiva dos portadores no mundo do qual fazem parte. Salienta-se, entretanto, que a implementação dessa metodologia em áreas endêmicas de filariose linfática não dispensa uma infra-estrutura em paralelo de médicos e de outros profissionais da saúde. Isso garantiria o diagnóstico diferencial com outras doenças potencialmente graves (malformação linfática, hanseníase, neoplasias malignas, entre outras) principalmente em pacientes que estão iniciando o seu quadro de (linfo)edema (ou de quilúria). Adicionalmente, as co-morbidades, que não são incomuns em pacientes portadores de disfunção linfática grave, tais como obesidade, hipertensão arterial, diabetes, úlcera varicosa, entre outras, também podem ser adequadamente avaliadas e tratadas, evitando-se um comportamento mais agressivo da progressão da doença linfática pré-existente.

\section{COMENTÁRIOS FINAIS}

0 Clube na Esperança, na sua forma original, foi desativado no segundo semestre de 2004, cerca de 20 meses antes da desativação do Núcleo de Ensino, Assistência e Pesquisa em Filariose - NEPAF. A ONG Amaury Coutinho e a UFPE têm planos de tornar o trabalho do NEPAF disponível na internet, principalmente na área de ensino e de consultoria. Para os sócios do Clube da Esperança, entretanto, esse modelo virtual não parece factível por muitas décadas ainda. Um dia, se isso acontecer, provavelmente, o portador de filariose crônica que habita as áreas mais pobres do planeta, também, não precisará mais desse tipo de ajuda e o Clube da Esperança perderá, assim, o seu sentido original. 0 acesso à Internet por esse tipo de população, na certa, coincidirá com o dia tão sonhado em que não existirão mais pessoas com potencialidade de se infectarem com a filariose. Pois, com certeza, a população hoje exposta já terá, nesse amanhã, 0 acesso aos bens públicos que impedem a proliferação do vetor e a transmissão da infecção filarial - o saneamento básico. Ousar sonhar é preciso. Cabe agora ao Estado julgar a importância da manutenção ou da implementação de Clubes da Esperança, nas diversas comunidades endêmicas, como parte dos programas oficiais e/ou institucionais verdadeiramente preocupados com 0 compromisso social, político e interdisciplinar existente em movimentos de natureza semelhante à do Clube da Esperança.

\section{AGRADECIMENTOS}

Os autores agradecem aos sócios do Clube da Esperança, pela contribuição na amplificação do conhecimento, extrapolando as fronteiras do Brasil, e pela constante inspiração aos profissionais e estudantes das diversas áreas do conhecimento que tiveram o privilégio de participar das reuniões. Aos amigos e colaboradores do programa de Filariose do CPqAM - Fiocruz, que ajudaram a convencer os primeiros pacientes (antes incrédulos), de forma carinhosa e com muito profissionalismo, de que eles poderiam ter uma vida melhor. Ao professor Gilson Edmar, diretor do Centro de Ciências da Saúde, por facultar o uso do espaço nobre da Universidade Federal de Pernambuco para a realização das reuniões, quando da transferência do Clube da Esperança do Centro de Pesquisas Aggeu Magalhães em 1998. À ONG Amaury Coutinho, pelo apoio financeiro para a manutenção da infra-estrutura necessária até 0 momento de sua desativação.

\section{REFERÊNCIAS BIBLIOGRÁFICAS}

1. Albuquerque MFM, Marzochi MC, Ximenes R, Braga MC, Silva MCM, Furtado AF. Bancroftian filariasis in two urban areas of Recife, Brasil: the role of individual risk factors. Revista do Instituto de Medicina Tropical de São Paulo 37:225-233, 1995.

2. Amaral F, Dreyer G, Figueredo-Silva J, Norões J, Cavalcanti A, Samico SF, Santos A, Coutinho A. Live adult worms detected by ultrasonography in human bancroftian filariasis. The American Journal of Tropical Medicine and Hygiene 50:753-757, 1994.

3. Casley-Smith JR. An electron microscopical study of the passage of ions through the endothelium of lymphatic and blood capillaries, and through the mesothelium. Quarterly Journal of Experimental Physiology 52:105$113,1967$.

4. Centers for Disease Control and Prevention. Recommendations of the International Task Force for Disease Erradication. Morbidity and Mortality Weekly Report - MMWR 42(RR-16):1-38, 1993. 
5. Centers for Diseases Control (CDC)/ONG Amaury Coutinho. Filariose Linfática: esperança para uma vida melhor. Vídeo educativo (em VHS e CD) em dois volumes (21 e 48 minutos para pacientes e agentes de saúde, respectivamente), em inglês, português, espanhol, criolo, francês e chinês, promovido e financiado pelo Centro Colaborador da OMS nas Américas Centers for Diseases Control (CDC) e a ONG Amaury Coutinho, 2000.

6. Dreyer G. Filariasis programme - Recife - Brazil. Memórias do Instituto Oswaldo Cruz 82:359-360, 1987.

7. Dreyer G. ONG Amaury Coutinho: transferência do conhecimento para o mundo real. Factível ou utopia? Revista da Sociedade Brasileira de Medicina Tropical 32:462-464, 1999.

8. Dreyer G, Addiss D. Hope clubs: new strategy for lymphatic filariasis endemic areas. Transactions of the Roval Society of Tropical Medicine and Hygiene - Bulletin of Tropical Medicine and International Health 8:8, 2000.

9. Dreyer G, Addiss D, Aguiar AM, Bettinger J, Dreyer P, Luiz A, Miguel S, Neves M, Peterson A. New hope: for people with lymphedema. Centers for Disease Control and Prevention - CDC, 1999.

10. Dreyer G, Addiss D, Dreyer P, Norões J. Basic lymphoedema management: treatment and prevention of problems associated with lymphatic filariasis. Hollis Publishing Co, Hollis, NH, 2002.

11. Dreyer G, Figueredo-Silva J, Carvalho K, Amaral F, Ottesen EA. Lymphatic filariasis in children: adenopathy and its evolution in two young girls. American Journal of Tropical Medicine and Hygiene 65:204-207, 2001.

12. Dreyer G, Mattos D, Norões J. Filariose Bancroftiana. In: Coura JR (ed) Dinâmica das Doenças Infecciosas e Parasitárias. Guanabara Koogan, Rio de Janeiro, p. 1087-1106, 2005.

13. Dreyer G, Medeiros Z, Netto MJ, Leal NC, De Castro LG, Piessens WF. Acute attacks in the extremities of persons living in an area endemic for bancroftian filariasis: differentiation of two syndromes. Transactions of the Royal Society of Tropical Medicine and Hygiene 93:413-417, 1999.

14. Dreyer G, Norões J. Filariose bancroftiana: o reverso das alterações orgânicas. Jornal Brasileiro de Psiquiatria 47:227-231, 1998.

15. Dreyer G, Norões J, Addiss D. The silent burden of sexual disability associated with lymphatic filariasis. Acta Tropica 63:57-60, 1997.

16. Dreyer G, Norões J, Figueredo-Silva J. Elimination of lymphatic filariasis as a public health problem. New insights into the natural history and pathology of bancroftian filariasis: implications for clinical management and filariasis control programs. Transactions of the Royal Society of Tropical Medicine and Hygiene 94:594-596, 2000.

17. Dreyer G, Norões J, Figueredo-Silva J, Piessens WF. Pathogenesis of lymphatic disease in bancroftian filariasis: a clinical perspective. Parasitology Today 16:544-548, 2000.
18. Fontes G, Braun RF, Fraiha Neto H, Vieira JBF, Padilha SS, Rocha RC, Rocha EMM. Filariose linfática em Belém, Estado do Pará, Norte do Brasil e a perspectiva de eliminação. Revista da Sociedade Brasileira de Medicina Tropical 38:131-136, 2005.

19. Harb M, Faris R, Gad AM, Hafez ON, Ramzy R, Buck AA. The resurgence of lymphatic filariasis in the Nile delta. Bulletin of the World Health Organization 71:49-54, 1993

20. Michael E, Bundy DAP, Grenfell BT. Re-assessing the global prevalence and distribution of lymphatic filariasis. Parasitology 112:409-428, 1996.

21. Norões J, Addiss D, Santos A, Medeiros Z, Coutinho A, Dreyer G. Ultrasonographic evidence of abnormal lymphatic vessels in young men with adult Wuchereria bancrofti infection in the scrotal area. Journal of Urology 156:409-412, 1996.

22. Olszewski WL, Jamal S, Manokaran G, Pani S, Kumaraswami V, Kubicka U, Lukomska B, Dworczynski A, Swoboda E, Meisel-Mikolajczyk F. Bacteriologic studies of skin, tissue fluid, lymph, and lymph nodes in patients with filarial lymphedema. The American Journal of Tropical Medicine and Hygiene 57:7-15, 1997.

23. Ottesen EA, Duke B0, Karam M, Behbehani K. Strategies and tools for the control/elimination of lymphatic filariasis. Bulletin of the World Health Organization 75:491-503, 1997.

24. Phillips AD. Determination of patients' ability to recognize interdigital lesions in bancroftian filariasis: self examination versus medical doctor examination. Tese de Mestrado, Universidade Estadual da Califórnia, Fresno, CSFU, 2000.

25. Seim AR, Dreyer G, Addiss D. Controlling morbidity and interrupting transmission: twin pillars of lymphatic filariasis elimination. Revista da Sociedade Brasileira de Medicina Tropical 32:325-328, 1999.

26. Universidade Federal de de Pernambuco (UFPE). Boletim Oficial 34:1-7, 1999.

27. Weil GJ, Lammie PJ, Weiss N. The ICT filariasis test: a rapid-format antigen test for diagnosis of bancroftian filariasis. Parasitology Today 13:401-404, 1997.

28. World Health Organization. The World Health Report 1995: Bridging the gaps. Geneva, World Health Organization, 1995.

29. World Health Organization. Fiftieth World Health Assembly, Geneva, 5-14 May 1997: resolutions and decisions; annexes. Geneva, (WHA50/1997/ REC/1) World Health Organization, 1997.

30. World Health Organization. Global Programme to Eliminate Lymphatic Filariasis: Annual Report on Lymphatic Filariasis 2001. Geneva, (WHO/ CDS/CPE/CEE/2002.28) World Health Organization, 2002. 